\title{
Recent advances in the immunogenetics of idiopathic inflammatory myopathy
}

\author{
Hector Chinoy 1,2, Janine A Lamb33, William ER Ollier ${ }^{3}$ and Robert G Cooper ${ }^{* 1,3}$
}

\begin{abstract}
This review summarizes the previous and current literature on the immunogenetics of idiopathic inflammatory myopathy (IIM) and updates the research progress that has been made over the past decade. A substantial part of the genetic risk for developing adult- and juvenile-onset IIM lies within the major histocompatibility complex (MHC), and a tight relationship exists between individual human leukocyte antigen alleles and specific serological subtypes, which in turn dictate clinical disease phenotypes. Multiple genetic regions outside of the $\mathrm{MHC}$ are increasingly being identified in conferring IIM disease susceptibility. We are still challenged with the task of studying a serologically and clinically heterogeneous disorder that is rarer by orders of magnitude than the likes of rheumatoid arthritis. An ongoing and internationally coordinated IIM genomewide association study may provide further insights into IIM immunogenetics.
\end{abstract}

\section{Introduction}

The idiopathic inflammatory myopathies (IIMs) represent a group of rare and heterogeneous 'orphan' autoimmune diseases characterized by inflammation of skeletal muscle and other organ systems, potentially leading to irreversible damage and resulting disability. The etiopathogenesis of IIM is likely to result from an interaction of genetic and environmental factors, which together are required to initiate the onset of a clinical disease phenotype [1]. IIMs traditionally have been classified broadly according to a limited set of subtypes: polymyositis (PM), dermatomyositis (DM), myositis overlapping with another

\footnotetext{
*Correspondence: robert.g.cooper@manchester.ac.uk

${ }^{1}$ Rheumatic Diseases Centre, Manchester Academic Health Science Centre, The University of Manchester, Salford Royal NHS Foundation Trust, Stott Lane, Salford, M6 8HD,UK

Full list of author information is available at the end of the article
}

connective tissue disease (myositis-CTD/overlap), inclusion body myositis (IBM), and juvenile dermatomyositis (JDM). However, serological status according to circulating myositis-specific antibodies (MSAs) or myositisassociated antibodies (MAAs) is proving to be increasingly useful in the classification of IIM and often correlates with defined IIM clinical phenotypes.

To date, our understanding of IIM immunogenetics has increasingly been facilitated by candidate gene studies examining the frequency of selected polymorphisms in IIM cases compared with controls. Historically, these studies have often included considerably heterogeneous IIM populations in order to increase statistical power. To facilitate meaningful research in rare diseases such as IIM, present and future approaches must include careful recruitment of confirmed ethnically homogeneous cohorts, and this requires collaboration across national and international recruitment centers. Already, new technologies mean that genome-wide association scans are now the norm in the genetic investigation of complex genetic diseases. The remit of this article is to discuss and summarize what is currently known about the immunogenetics of IIM and to concentrate on candidate gene studies that currently provide the best evidence for a genetic basis in IIM.

\section{The evidence for a genetic basis in myositis}

There is increasing evidence to suggest a genetic basis in IIM, but owing to the scarcity of affected sibling pairs and twins, this evidence currently comes from anecdotal familial aggregation and candidate gene studies only $[2,3]$. To date, no IIM familial linkage or twin studies have been published, and the 'heritability' of the disease $(\lambda s)$ is unknown. The scarcity of familial IIM cases suggests that, when encountering two or more first-degree family members with symptoms and signs in keeping with possible IIM, attending physicians should be highly suspicious of making such diagnoses without careful clinicopathological correlation. If necessary, DNA or further biochemical analysis or both should also be conducted at a specialized neuromuscular center to exclude non-inflammatory forms of neuromuscular disease such as dystrophies, mitochondrial, or metabolic myopathies. 


\section{Familial aggregation in myositis}

The evidence for familial aggregation in IIM arises from case reports, the first of which was by Wedgwood and colleagues [4], who described JDM in twins, whose onset occurred within a year of each other. Other cases, in which two or more family members suffer from IIM (including DM, PM, IBM, and orbital and amyopathic myositis), have since been described [2].

Rider and colleagues [5] recruited 36 patients with PM, DM, or IBM from 16 unrelated families in which two or more individuals fulfilled criteria for probable or definite myositis. A cohort of non-familial IIM cases $(n=181)$ was used as a comparison group. MSAs were more frequent in the non-familial compared with the familial myositis group. HLA-DRB1*0301 was a significant risk factor in both familial and non-familial disease versus controls, but the genetic contribution in familial cases was less than that of non-familial cases (attributable risk of 0.35 versus 0.51). Homozygosity in a combined analysis of all studied HLA-DQA1 alleles combined proved a risk factor for familial disease. The modest differences between familial/non-familial IIM cases suggest that there may be further as-yet-unidentified environmental and genetic factors in IIM [5].

\section{HLA candidate gene studies}

To date, the strongest immunogenetic associations found in IIM arise from the MHC region in a fashion analogous to that of other autoimmune diseases [6]. Given the rarity of IIM, early candidate gene studies examined only small numbers of patients and often grouped clinical IIM subgroups together (including PM, DM, IBM, and JDM) in an effort to increase statistical power. In some early studies, even patients of differing ethnic groups were examined together. Studies in the last 5 years have attempted to address these case-selection issues by stratifying cases according to ethnic, clinical, and serological subtypes.

Alleles forming part of the 8.1 Caucasian MHC common ancestral haplotype (HLA-A1-B8-Cw7DRB1*0301-DQA1*0501-C4A*Q0) occur in strong linkage disequilibrium within Caucasian populations in Northern and Western Europe, and this haplotype represents a risk factor for a large number of immunopathological diseases [7]. To date, the 8.1 haplotype has also been identified as a major risk factor in IIM (Table 1) [5,8-22].

The HLA associations observed in IIM subgroups of Caucasian ethnicity are not generally found in other nonCaucasoid populations, although alleles of the 8.1 haplotype have been described in two studies of AfricanAmerican IIM $[11,18]$. No HLA associations have been found in Mexican-American or Korean myositis popu- lations, illustrating the importance of stratification by ethnicity in such studies $[10,12]$.

Recent larger studies have enabled the identification and characterization of HLA alleles that act as risk as well as protective factors in different IIM phenotypes. For example, HLA-DRB1*0301 represents a strong PM risk factor whereas HLA-DQA1*0201 confers protection in the same clinical phenotype $[12,13]$. The concept of shared alleles within defined haplotypes may also contribute to this. For example, in PM, the high frequency of the 8.1 haplotype may be responsible, in part, for lowering the frequency of DRB1*07-DQA1*02-DQB1*02 and this is due to the shared DQB1*02 allele within both haplotypes. This combination of risk and protection may contribute to the stability and exclusivity of IIM phenotypes [23]. A primary amino acid sequence of HLA-DRB1 alleles known to share a peptide-binding motif has been described in IIM. This sequence is called ${ }^{9}$ EYSTS $^{13}$ and refers to the first hypervariable HLA-DRB1 region sequence, which is shared by the DRB1*03, 11, 13, and 14 alleles (Table 1). A strong association has been found for anti-Mi-2 positivity in a polymorphism that also incorporates the first hypervariable region but that codes for an aromatic tryptophan residue at position 9 (HLADRB*01, 02, 07) [24]. Further HLA peptide-binding motifs and haplotypes that are both risk and protective factors in IIM have been described in larger-scale studies. These findings emphasize the importance of HLA haplotypes and peptide-binding motifs in discriminating between IIM clinical and serological subtypes [12,13,25].

\section{HLA associations with myositis autoantibodies}

HLA alleles are known to be strongly associated with the likelihood of developing MSAs/MAAs in IIM, in which the strength of association is considerably greater than that in association with stratification by traditional clinical subtype (Table 2) $[9,11,13,16,18,24-28]$. This suggests that stratification by serological, rather than traditional clinical, subtype represents a more homogeneous form of IIM classification [13,29].

The association of anti-Jo-1 antibodies and alleles comprising the 8.1 haplotype has been confirmed in several studies [11,13,29-31]. This strong relationship between HLA and serological subtype is also present for other MSAs/MAAs, in which antibodies other than anti-Jo-1 are associated with other haplotypes. However, HLA alleles comprising the 8.1 haplotype are also strongly associated with the presence of anti-PM-Scl antibodies, an MAA often associated with myositis/sclerodema overlap syndrome [28]. This antibody/phenotype association has been confirmed in a UK JDM population [15]. Mierau and colleagues [24] demonstrated that HLADRB1*0701 represented a strong risk factor in German Caucasian anti-Mi-2 antibody-positive patients versus 
Table 1. HLA associations in ethnically different myositis populations

\begin{tabular}{|c|c|c|c|}
\hline Population & Ethnicity & Allele & Reference \\
\hline$\| \mathrm{M}$ & Caucasian & HLA common ancestral Haplotype (A1;B8;DR3) & {$[5,8-15]$} \\
\hline$\| \mathrm{M}$ & Caucasian & EYSTS, DRB1 HVR motif & {$[10,12,14]$} \\
\hline PM & Caucasian & $\begin{array}{l}\mathrm{CW}^{*} 0701 \\
\text { DRB1*0401 (protective) } \\
\text { DQA1*0201 (protective) }\end{array}$ & [12] \\
\hline PM & Caucasian & $\begin{array}{l}\text { DRB }{ }^{*} 07 \text { (protective) } \\
\text { DQA }{ }^{* 02} \text { (protective) }\end{array}$ & [13] \\
\hline PM & Caucasian & $\mathrm{DPB} 1 * 0101$ & [16] \\
\hline DM & Caucasian & $\begin{array}{l}\text { A*68 }^{*} \\
\text { DQA1*01 (protective) }\end{array}$ & [12] \\
\hline Familial IIM & Caucasian & DQA1 homozygosity & [5] \\
\hline$J D M$ & Caucasian & $\mathrm{DMA}^{*} 0103$ & [17] \\
\hline$\| \mathrm{M}$ & African-American & DRB $1 * 14$ (protective) & [18] \\
\hline$\| \mathrm{M}$ & African-American & B7; DRw6 & [19] \\
\hline DM/JDM & African-American & DRB1*0301 & [18] \\
\hline JDM & African-American & DQA1*0501 & [20] \\
\hline JDM & Hispanic & DQA $1 * 0501$ & [20] \\
\hline $\mathrm{JDM}$ & Hispanic & DR3 & [21] \\
\hline PM & Japanese & DRB $1 * 0803$ & [22] \\
\hline
\end{tabular}

All listed risk/protective factors are risk alleles/haplotypes unless stated otherwise. Data are presented only if results remain significant after corrections for multiple comparisons are applied to probability values. DM, dermatomyositis; IIM, idiopathic inflammatory myopathy; JDM, juvenile dermatomyositis; PM, polymyositis.

controls. This association has since been confirmed in larger studies [13,25,26]. HLA-DQA1*0201, known to share strong linkage disequilibrium with DRB1*0701, also confers risk in anti-Mi-2 antibody-positive cases. The strong relationship between HLA and these MSAs/ MAAs may partly explain the exclusivity that these antibodies possess, as illustrated by the extreme rarity of multiple MSAs in the same patient. It is currently unclear whether strong associations exist with HLA alleles among rarer MSAs, although a recent US study has identified potential genetic risk factors for SRP and the less frequent anti-synthetases [25].

These HLA-related risk factors among serological subgroups clearly differ according to ethnicity (Tables 1 and 2HLA associations in ethnically different myositis populations). For example, African-Americans with IIM do not share the 8.1 haplotype-related risk in the same way as Caucasians. However, a recent large-scale US study showed that African-Americans with either DM or anti-Jo-1 antibodies do appear to share the risk of HLADRB1*0301 with Caucasians [18]. Furthermore, HLADRB1*0302 is a significant risk factor for anti-Mi-2 antibody-positive African-American cases. This latter allele shares amino acid side chains coded for by the Caucasian anti-Mi-2 risk factor DRB1*0701, and further comparative analyses suggested identical orientations within the peptide-binding groove. In a recent smaller study of UK-based non-Caucasians, HLA-DRB1*03 was also detected as a risk factor in anti-Mi-2 and anti-PM$\mathrm{Scl}$ antibody-positive cases [32]. The issue of shared HLA susceptibility risk factors across ethnic groups may suggest affinity for common antigenic peptides. However, the results of these non-Caucasoid studies also highlight that the between-ethnic differences demonstrated for myositis genotype, serotype, and phenotype need to be taken into account when making future case-case or case-control comparisons.

\section{Tumor necrosis factor-alpha}

TNF- $\alpha$ is a proinflammatory cytokine with a diverse range of activities, playing a major role in immune response regulation. The $T N F-\alpha$ gene is encoded within the MHC class III region, and associated SNPs have been implicated in many autoimmune diseases, including dermatitis herpetiformis, systemic lupus erythematosus, ankylosing spondylitis, and Crohn's disease, and also in various infectious diseases, including malaria, leprosy, and hepatitis $\mathrm{B} / \mathrm{C}[7]$.

A TNF- $\alpha$ promoter SNP at position -308 (rs1800629), resulting from a G-to-A substitution has been associated with IIM in a number of candidate gene studies [33-36]. In a recent juvenile DM study, homozygosity for the $\mathrm{A}$ allele of the TNF $\alpha-308$ SNP was shown to confer risk for soft-tissue calcinosis (9\% calcinosis versus $1 \%$ no calcinosis, corrected $P$ value $\left(P_{\text {corr }}\right)=0.045$, odds ratio $(\mathrm{OR})$ 7.3, 95\% confidence interval (CI) 1.4 to 37.2) [36], 
Table 2. HLA associations in IIM serological groups by ethnicity

\begin{tabular}{|c|c|c|c|c|c|}
\hline Antibody & Ethnicity & Allele & $P$ value & $\mathrm{OR}, 95 \% \mathrm{Cl}$ & Reference \\
\hline \multirow[t]{9}{*}{ Anti-Jo-1 } & Caucasian & DRB1*0301 & $P=0.00004$ & $9.6,2.9-36.3$ & [11] \\
\hline & & & $P_{\text {corr }}<0.0001$ & $15.5,8.3-30.2$ & [25] \\
\hline & & $\mathrm{DQB} 1 * 0201$ & $P=0.0002$ & $8.3,2.2-46.1$ & [11] \\
\hline & & $B^{*} 08$ & $P_{\text {corr }}<0.0001$ & $21.7,9.4-55.4$ & [25] \\
\hline & & $C^{*} 0701$ & $P_{\text {corr }}<0.0001$ & $15.7,6.4-41.5$ & \\
\hline & & $D R B 1 * 01$ & $P_{\text {corr }}=0.008$ & $0.3,0.1-0.6$ & \\
\hline & & $D Q A 1 * 0201$ & $P_{\text {corr }}<0.0001$ & $0.1,0.1-0.4$ & \\
\hline & & DQA1*0501 & $P_{\text {corr }}<0.0001$ & $5.1,2.7-10.4$ & \\
\hline & & DPB1*0101 & $P_{\text {corr }}<0.00003$ & $4.1,2.1-7.8$ & [16] \\
\hline \multirow[t]{2}{*}{ Anti-Jo-1 } & African-American & $B^{*} 08$ & $P=0.02$ & $7.6,2.1-27.4$ & [18] \\
\hline & & DRB1*0301 & $P=0.001$ & $6.7,2.5-18.0$ & \\
\hline Anti-PL-7 & Caucasian & $C^{*} 0304$ & $P_{\text {corr }}=0.05$ & $25.3,2.2-1,257.8$ & [25] \\
\hline Anti-PL-12 & Caucasian & DRB1*0301 & $P_{\text {corr }}=0.01$ & $13.5,2.6-131.2$ & [25] \\
\hline \multirow[t]{5}{*}{ Anti-synthetase } & Caucasian & $\mathrm{DRB} 1 * 03$ & $P_{\text {corr }}=1 \times 10^{-14}$ & $14.1,6.3-35.2$ & [13] \\
\hline & & $\mathrm{DRB} 1 * 0301$ & $P_{\text {corr }}<0.008$ & $40.1,4.2-1,861$ & [9] \\
\hline & & DQA $1 * 05$ & $P_{\text {corr }}=4 \times 10^{-8}$ & $9.5,3.8-36.5$ & [13] \\
\hline & & DQA1*0501 & $P_{\text {corr }}<0.008$ & $16.7,1.9-770.2$ & [9] \\
\hline & & $\mathrm{DQB} 1{ }^{*} 02$ & $P_{\text {corr }}=4 \times 10^{-8}$ & $9.5,3.8-36.5$ & [13] \\
\hline \multirow[t]{9}{*}{ Anti-Mi-2 } & Caucasian & $\mathrm{DRB} 1{ }^{*} 07$ & $P_{\text {corr }}=0.00005$ & $11.1,3.4-46.8$ & [13] \\
\hline & & $\mathrm{DRB} 1 * 0701$ & $P<0.0001$ & $22,4.6-105$ & [24] \\
\hline & & & $P<0.001$ & $18.7,2.1-873.4$ & [26] \\
\hline & & & $P_{\text {corr }}=0.002$ & $4.9,2.2-11.5$ & [25] \\
\hline & & $\mathrm{DQA} 1 * 02$ & $P_{\text {corr }}=0.00005$ & $11.6,3.3-50.6$ & [13] \\
\hline & & DQA1*0201 & $P<0.0001$ & $20.2,4.4-93$ & [24] \\
\hline & & & $P<0.001$ & $19.8,2.2-923.3$ & [26] \\
\hline & & & $P_{\text {corr }}=0.002$ & $3.3,1.5-7.5$ & [25] \\
\hline & & $\mathrm{DQB} 1 * 02$ & $P_{\text {corr }}=0.004$ & $7.5,2.0-41.9$ & [13] \\
\hline \multirow[t]{2}{*}{ Anti-Mi-2 } & Hispanic & $\mathrm{DRB} 1 * 04$ & $P_{\text {corr }}<0.01$ & $4.7,1.7-13.3$ & [26] \\
\hline & & $\mathrm{DQA} 1 * 03$ & $P_{\text {corr }}<0.001$ & $7.0,2.3-22.8$ & \\
\hline \multirow[t]{2}{*}{ Anti-Mi-2 } & African-American & DRB1*0302 & $P=0.0005$ & $23.6,4.2-234.2$ & [25] \\
\hline & & DQA1*0401 & $P=0.0008$ & $25.2,3.2-1,106$ & \\
\hline Anti-SRP & Caucasian & $B^{*} 5001$ & $P_{\text {corr }}=0.02$ & & [25] \\
\hline Anti-SRP & African-American & DQA1*0101 & $P=0.04$ & $3.6,1.4-9.8$ & [18] \\
\hline \multirow[t]{10}{*}{ Anti-PM-SCl } & Caucasian & $\mathrm{DRB} 1{ }^{*} 03$ & $P<0.0001$ & & [27] \\
\hline & & & $P<0.0001$ & $10.6,3.4-38.7$ & [28] \\
\hline & & & $P_{\text {corr }}=0.00004$ & $30.6,4.4-1,309.1$ & [13] \\
\hline & & DRB1*0301 & $P_{\text {corr }}<0.008$ & $100,13.1-4,258$ & [9] \\
\hline & & & $P_{\text {corr }}<0.0001$ & $77.5,19.6-663.8$ & [25] \\
\hline & & $D Q A 1 * 0101$ & $P_{\text {corr }}=0.003$ & $0.2,0.05-0.5$ & {$[25]$} \\
\hline & & DQA1*05 & $P_{\text {corr }}=0.001$ & $18.9,2.6-814.9$ & [13] \\
\hline & & DQA $1 * 0501$ & $P_{\text {corr }}<0.008$ & $16.5,1.9-763.4$ & [9] \\
\hline & & & $P_{\text {corr }}<0.0001$ & $15.2,4.8-77.1$ & [25] \\
\hline & & $\mathrm{DQB} 1 * 02$ & $P_{\text {corr }}=0.001$ & $18.0,2.5-777.4$ & [13] \\
\hline \multirow[t]{3}{*}{ Anti-Ku } & Caucasian & $\mathrm{DRB} 1 * 0301$ & $P_{\text {corr }}<0.008$ & $38.1,4.1-1,768$ & [9] \\
\hline & & DQA1*0501 & $P_{\text {corr }}<0.008$ & $16.5,1.9-763.4$ & \\
\hline & & DRB1*11 & $P_{\text {corr }}<0.04$ & $21.3,2.1-1,049.8$ & [25] \\
\hline
\end{tabular}

$P$ values are uncorrected (unless otherwise stated), and associations given are odds ratios (ORs) and $95 \%$ confidence intervals (Cls) versus controls. Alleles in italics refer to protective factors. $P_{\text {corr' }}$ corrected $P$ value. 
findings consistent with those from a previous study [33]. However, in both adult and juvenile IIM, other alleles forming part of the 8.1 haplotype have been reported to confer the primary association over and above that resulting from $T N F \alpha-308 \mathrm{~A}[36,37]$.

It is known that subjects with the 8.1 haplotype have an altered immune response and thus immune stress may produce an imbalanced array of cytokines [38]. In a study of normal subjects, stratified by the presence or absence of the 8.1 haplotype, TNF- $\alpha$ levels in both serum and stimulated mononuclear cells were significantly higher in 8.1 haplotype-positive versus -negative carriers $(P<0.0005)$ [39]. Studies have suggested a genetic contribution to TNF- $\alpha$ regulation, in which $T N F \alpha-308 \mathrm{~A}$ and other $T N F-\alpha$ gene polymorphisms are associated with higher-circulating levels of TNF- $\alpha$ [40]. These findings have also been suggested from IIM studies [33]. B-cell activating factor (BAFF) and a proliferation-inducing ligand (APRIL) are members of the TNF superfamily and have key functions in both B- and T-cell homeostasis, and both ligands are significantly increased in the serum of IIM cases versus controls [41]. The $T N F \alpha-308 \mathrm{~A}$ polymorphism therefore may have functional significance in driving an altered immune response. Supporting evidence for this comes from a gene expression study in juvenile DM, the results of which suggested that TNF- $\alpha$ was a key molecule within a pathogenesis model that included antiviral, ischemic, and degeneration/regeneration processes [42]. However, identification of the relevant functional variant at the TNF- $\alpha$ locus is complicated by the presence of extensive linkage disequilibrium within this region.

\section{HLA-DPB1 associations}

Genetic variations outside of the traditional 8.1 haplotype region may be involved in determining serotype/phenotype differences. The HLA-DPB1 gene lies at the centromeric end of MHC and is separated from other HLA class II loci by one or more genetic recombination hotspots, which may weaken the degree of any linkage disequilibrium with other class II loci [43].

In a UK-based cohort of 311 adult- and juvenile-onset PM, DM, or myositis/CTD-overlap cases, a strong association was observed between HLA-DPB1*0101 and the presence of anti-Jo-1 antibodies (Table 1) [44]. Despite the strong association of HLA-DRB1*03 with both antiJo-1 and anti-PM-Scl antibodies, no significant difference was noted in the frequency of HLA-DPB1*0101 between anti-PM-Scl antibody-positive cases (15\%) and controls (13\%). Furthermore, a significant difference at HLADPB1*0101 was noted when anti-Jo-1- and PM-Sclpositive cases were compared with each other, and this allele was much more common in anti-Jo-1 cases (37\% Jo-1 versus $15 \%$ PM-Scl, uncorrected $P=0.03$, OR 3.3, $95 \%$ CI 1.01 to 12.7). Thus, additional disease susceptibility signals for anti-Jo-1 may be present in the centromeric end of the MHC region. These additional signals genetically discriminate risk for anti-Jo-1 from that of anti-PM-Scl antibodies. Fine mapping and further detailed HLA analyses in large-scale collaborations are now required within the MHC to carefully investigate these differences.

\section{Progress outside of major histocompatibility complex \\ Mannose-binding lectin 2 polymorphisms}

Mannose-binding lectin (MBL2) is a protein that may play a role in reducing photosensitive autoimmunity by altering the clearance of apoptotic cells [45]. Several polymorphisms have been described in the $M B L$ gene and can affect serum MBL concentrations. One such SNP (Gly $\rightarrow$ Asp, codon 42, exon 1, rs1800450), known to be associated with low serum MBL concentrations, was studied in a small US study comparing DM cases with cutaneous lupus erythematosus cases and controls [45]. This $M B L$ polymorphism was significantly increased in $\mathrm{DM}(P=0.0004)$ but not cutaneous lupus erythematosus versus controls. Combinations of low-producing $M B L$ variants were also associated with $\mathrm{DM}$, but again not in subacute cutaneous lupus erythematosus. It was thus hypothesized that these MBL polymorphisms could influence the pathogenesis of DM by influencing overproduction of apoptotic keratinocytes and impairing the clearance of such apoptotic cells.

\section{Immunoglobulin gene polymorphisms}

Immunoglobulin gene polymorphisms encoding constant regions of immunoglobulin gamma heavy (GM, 14q32.33) and kappa light $(\mathrm{KM}, 2 \mathrm{p} 12)$ chains have been examined in a series of US Caucasian and African-American IIM cohorts $[10,26,46]$. A number of studies have examined individuals with allelic variants of specific GM/KM genes, in which raised titres of specific IgG antibody subclasses were present, against various antigenic epitopes of infectious disease agents or self-proteins [46]. The most recent study of GM/KM allotypes, in 514 US Caucasian and 123 African-American adult/juvenile IIM cases [46], adds to previous studies of Mesoamerican and Korean populations $[10,26]$. The GM 13 allotype showed the strongest association in Caucasian juvenile DM versus controls $\left(P_{\text {corr }}<0.0001\right.$, OR 3.9, 95\% CI 2.26 to 6.76). When analyzed as a paired combination with either the KM 1 or 3 allotype, the GM marker also conferred risk in Caucasian adult IIM ( $P_{\text {corr }}<0.004$ for each pair). In adults, the GM 3235,13 phenotype was significantly increased in anti-Jo-1 antibody-positive adult DM cases versus controls $\left(P_{\text {corr }}=0.0031\right.$, OR 3.4, 95\% CI 1.68 to 7.12). Other $\mathrm{GM} / \mathrm{KM}$ markers also differentiated between the Caucasian and African-American cohorts. 
These results indicate mechanistic interactions between two independent loci outside of the HLA system. It would be interesting to examine these markers in geographically diverse populations to confirm the findings and to further test the apparent ethnic heterogeneity with these loci.

\section{Protein tyrosine phosphatase $\mathrm{N} 22$}

Previous large-scale genetic association studies have confirmed a missense SNP in the protein tyrosine phosphatase N22 (PTPN22) gene in association with a variety of autoimmune diseases [47]. At position 1858 of the PTPN22 gene, a $\mathrm{C} \rightarrow \mathrm{T}$ change (rs2476601) leads to an amino acid substitution (arginine $\rightarrow$ tryptophan, R620W) in the lymphocyte phosphatase (LYP) protein, thought to be a 'gain-of-function mutation'. The LYP*W620 is able to dephosphorylate signaling proteins more efficiently than LYP*R620, leading to increased T- and B-lymphocyte inhibition, thymic hypo-responsiveness, and an increase in circulating autoreactive T cells [48]. The PTPN22 gene has been investigated in a large, adult and juvenile UK IIM cohort [49]. The results showed that the R620W polymorphism was associated with the combined adult/ juvenile IIM group (13.6\% IIM versus $8.2 \%$ controls, $P_{\text {corr }}<0.0009$, OR $1.8,95 \%$ CI 1.3 to 2.4 ) and also within the adult PM (16.4\% PM, $P_{\text {corr }}=0.003$, OR 2.2, 95\% CI 1.4 to 3.3$)$ and juvenile DM (15.9\% juvenile DM, $P_{\text {corr }}=0.009$, OR 2.1, 95\% CI 1.3 to 3.3) subgroups. Importantly, this IIM/PTPN22 association was shown to be independent of the 8.1 haplotype. Other PTPN22 SNPs were examined, but only a haplotype incorporating the minor $\mathrm{T}$ allele of R620W conferred any significant degree of susceptibility for IIM. Unlike the described HLA associations with IIM, no associations were observed within serological subgroups after corrections for multiple comparisons. Thus, the R620W variant appears to be a risk factor for IIM regardless of MSA/MAA status, implying a risk for general autoimmunity rather than conferring risk for a specific serological subtype (cf HLA) The effect size of this SNP in conferring risk for IIM is in keeping with observations for other autoimmune diseases such as rheumatoid arthritis.

\section{Interleukin 1}

Proinflammatory cytokines such as TNF- $\alpha$ and interleukin 1 (IL1) $\alpha / \beta$ are overexpressed in inflammatory cell infiltrates and on the surface of skeletal muscle cells in IIM muscle biopsy samples. IL $1 \alpha / \beta$ are also overexpressed in capillary endothelium in affected IIM muscle. A recent study examined $I L 1$ cytokine polymorphisms in juvenile DM [36]. The $I L 1 B+3953$ T allele polymorphism (rs1143634) conferred risk (53\% IIM versus 40\% controls, $P_{\text {corr }}=0.038$, OR $1.7,95 \%$ CI 1.1 to 2.6 ) and the IL1A+4845G polymorphism (rs17561) was protective for juvenile DM (77\% IIM versus 88\% controls, $P_{\text {corr }}=0.011$, OR $0.46,95 \%$ CI 0.27 to 0.79 ). Other possible cytokine gene associations with IIM (interferon gamma, chemokine ( $\mathrm{C}-\mathrm{C}$ motif) receptor 2 ) have been investigated in UK adult IIM studies, but no robust associations were found $[50,51]$.

\section{Inclusion body myositis}

The recent larger-scale IIM candidate gene studies already cited have not concentrated on IBM, and, consequently, little progress has been made in the study of IBM immunogenetics. Previous IBM genetic studies have contained only small numbers of patients and have concentrated on the HLA region [3,52]. Consequently, global collaborative efforts between neurology and rheumatology are now required to readdress this recruitment issue.

A recent study investigated HLA class I and II associations in a cohort of 80 Australian sporadic IBM cases compared with 190 controls [53]. The association with HLA-DR3 and IBM was confirmed (75\% IBM versus 23\% controls, $P<0.01$, OR $9.56,95 \%$ CI 5.12 to 18.96$)$. In a case-control subanalysis of DR3-positive carriers, the frequency of HLA-DR3/DR1 heterozygotes was significantly increased in IBM compared with controls $(P<0.003)$. Within this subgroup, the mean age of onset of disease was significantly lower when compared with the remaining patients (55.8 years versus 62.3 years, $P=$ $0.006)$. The average quadriceps femoris muscle strength was lower in HLA-DR3-positive compared with HLADR3-negative cases after disease duration and treatment were adjusted for $(P=0.01)$, confirming the findings of a previous study [54]. Such a result may suggest that the 8.1 haplotype not only influences susceptibility for IBM but also may affect clinical disease expression.

Similarities have previously been noted in accumulated proteins from sporadic IBM muscle biopsies and brain tissue plaques from Alzheimer's disease cases, including amyloid- $\beta$ precursor protein, amyloid- $\beta$, and apolipoprotein E (apoE) [55]. The APOE gene was previously investigated in sporadic IBM [52]. A gene expression mRNA profiling study has demonstrated the increased expression of amyloid and apoE in IBM, but significantly elevated levels of the same genes were also found in the biopsies of PM and DM cases (in which the expression of these proteins is not typically found). These findings suggest that the observed accumulation of these proteins in IBM may be due to post-transcriptional events downstream of mRNA expression [56].

\section{Dissecting genetic associations to identify the functional variants}

As indicated above, it is becoming increasingly clear from published research that multiple genes and genetic 
variants, acting in a variety of biological pathways, are involved in susceptibility to autoimmune disorders. Identification of the precise role of specific HLA alleles is complicated by the presence of extensive linkage disequilibrium across common autoimmune risk haplotypes; analyses conditional on known genetic risk variants have been carried out in an attempt to alleviate this problem and to identify independent signals. Furthermore, the majority of research to date has been published on Caucasian populations, and it is not yet clear how much variability in disease susceptibility there is between different ethnic groups. Further multiethnic comparisons may help to identify the functional genetic variants and to interpret differences in clinical presentation and disease severity between different populations.

\section{Conclusions}

This review illustrates the progress that has been made in IIM immunogenetic research over the past decade. A substantial part of the genetic risk for developing adultand juvenile-onset IIM lies within the MHC, but multiple genetic regions outside of the $\mathrm{MHC}$ are increasingly being identified as conferring disease susceptibility risk. There is still the challenge of studying a serologically heterogeneous disorder that is rarer by orders of magnitude than the likes of rheumatoid arthritis. Nevertheless, findings increasingly appear to demonstrate the strong relationship between HLA genotype and IIM serological/clinical phenotype. Further and larger collaborative studies will help to discern whether an individual's genotype will assist the attending physician in the assessment of disease severity and outcome. Through MYOGEN, a fully international Myositis Genetics Consortium, a genome-wide association scan is already being undertaken and analyzed. It is hoped that the results will repeat the successes already demonstrated in other autoimmune diseases and that post-genomic work in IIM will result in the identification of novel disease susceptibility variants. Exciting times beckon in the difficult field of IIM immunogenetics!

Autoimmune Basis of Rheumatic Diseases

This article is part of a series on Myositis, edited by Ingrid Lundberg, which can be found online at

http://arthritis-research.com/series/myositis

This series forms part of a special collection of reviews covering major autoimmune rheumatic diseases, available at:

http://arthritis-research.com/series/abrd

\section{Abbreviations}

apoE, apolipoprotein $\mathrm{E} ; \mathrm{Cl}$, confidence interval; DM, dermatomyositis; IBM, inclusion body myositis; IIM, idiopathic inflammatory myopathy; IL, interleukin; JDM, juvenile dermatomyositis; LYP, Iymphocyte phosphatase; MAA, myositis-associated antibody; MBL, mannose-binding lectin; MHC, major histocompatibility complex; MSA, myositis-specific antibody; OR, odds ratio; $P$ corr corrected $P$ value; PM, polymyositis; PTPN22, protein tyrosine phosphatase N22; SNP, single-nucleotide polymorphism; TNF, tumor necrosis factor.

\section{Competing interests}

The authors declare that they have no competing interests.

\section{Acknowledgments}

We wish to thank Arthritis Research UK for providing the infrastructure that made this collection of adult myositis patients'DNA samples possible and the Myositis Support Group (UK), which provided the funds necessary to undertake the genetic analysis presented. We thank the patients and their families for agreeing to contribute to the National JDM Registry and Repository (UK and Ireland) and Juvenile Dermatomyositis Research Group contributors, who are cited in [15]. We thank the UK physicians who contributed to the Adult Onset Myositis Immunogenetic Collaboration. Their names and affiliations are cited in [13]

\section{Author details}

${ }^{1}$ Rheumatic Diseases Centre, Manchester Academic Health Science Centre, The University of Manchester, Salford Royal NHS Foundation Trust, Stott Lane, Salford, M6 8HD,UK. ${ }^{2}$ Musculoskeletal Research Group, School of Translational Medicine, Manchester Academic Health Science Centre, The University of Manchester, Oxford Road, M13 9PT Manchester, UK. ${ }^{3}$ Centre for IIntegrated Genomic Medical Research, Manchester Academic Health Science Centre, The University of Manchester, Oxford Road, M13 9PT Manchester, UK.

Published: 26 May 2011

\section{References}

1. Cooper GS, Miller FW, Pandey JP: The role of genetic factors in autoimmune disease: implications for environmental research. Environ Health Perspect 1999, 107 Suppl 5:693-700.

2. Shamim EA, Rider LG, Miller FW: Update on the genetics of the idiopathic inflammatory myopathies. Curr Opin Rheumatol 2000, 12:482-491.

3. Chinoy $\mathrm{H}$, Ollier WE, Cooper RG: Have recent immunogenetic investigations increased our understanding of disease mechanisms in the idiopathic inflammatory myopathies? Curr Opin Rheumatol 2004, 16:707-713.

4. Wedgwood RJ, Cook CD, Cohen J: Dermatomyositis; report of 26 cases in children with a discussion of endocrine therapy in 13. Pediatrics 1953, 12:447-466.

5. Rider LG, Gurley RC, Pandey JP, Garcia de la Torre I, Kalovidouris AE, O'Hanlon TP, Love LA, Hennekam RC, Baumbach LL, Neville HE, Garcia CA, Klingman J, Gibbs M, Weisman MH, Targoff IN, Miller FW: Clinical, serologic, and immunogenetic features of familial idiopathic inflammatory myopathy. Arthritis Rheum 1998, 41:710-719.

6. Ollier W: The genetic basis of rheumatic disease. In Rheumatology. 3rd edition. Edited by Hochberg MC, Silman AJ, Smolen JS, Weinblatt ME, Weisman MH. City: Mosby; 2003:99-111.

7. Price P, Witt C, Allcock R, Sayer D, Garlepp M, Kok CC, French M, Mallal S, Christiansen $\mathrm{F}$ : The genetic basis for the association of the 8.1 ancestral haplotype (A1, B8, DR3) with multiple immunopathological diseases. Immunol Rev 1999, 167:257-274.

8. Reed AM, Pachman LM, Hayford J, Ober C: Immunogenetic studies in families of children with juvenile dermatomyositis. J Rheumatol 1998 , 25:1000-1002.

9. Hausmanowa-Petrusewicz I, Kowalska-Oledzka E, Miller FW, JarzabekChorzelska M, Targoff IN, Blaszczyk-Kostanecka M, Jablonska S: Clinical, serologic, and immunogenetic features in Polish patients with idiopathic inflammatory myopathies. Arthritis Rheum 1997, 40:1257-1266.

10. Rider LG, Shamim E, Okada S, Pandey JP, Targoff IN, O'Hanlon TP, Kim HA, Lim YS, Han H, Song YW, Miller FW: Genetic risk and protective factors for idiopathic inflammatory myopathy in Koreans and American whites: a tale of two loci. Arthritis Rheum 1999, 42:1285-1290.

11. Arnett FC, Targoff IN, Mimori T, Goldstein R, Warner NB, Reveille JD: Interrelationship of major histocompatibility complex class II alleles and autoantibodies in four ethnic groups with various forms of myositis. Arthritis Rheum 1996, 39:1507-1518.

12. O'Hanlon TP, Carrick DM, Arnett FC, Reveille JD, Carrington M, Gao X, Oddis CV, Morel PA, Malley JD, Malley K, Dreyfuss J, Shamim EA, Rider LG, Chanock SJ, Foster CB, Bunch T, Plotz PH, Love LA, Miller FW: Immunogenetic risk and 
protective factors for the idiopathic inflammatory myopathies: distinct HLA-A, -B, -Cw, -DRB1 and -DQA1 allelic profiles and motifs define clinicopathologic groups in caucasians. Medicine (Baltimore) 2005, 84:338-349.

13. Chinoy H, Salway F, Fertig N, Shephard N, Tait BD, Thomson W, Isenberg DA, Oddis CV, Silman AJ, Ollier WE, Cooper RG; UK Adult Onset Myositis Immunogenetic Collaboration (AOMIC): In adult onset myositis, the presence of interstitial lung disease and myositis specific/associated antibodies are governed by HLA class II haplotype, rather than by myositis subtype. Arthritis Res Ther 2006, 8:R13.

14. Mamyrova G, O'Hanlon TP, Monroe JB, Carrick DM, Malley JD, Adams S, Reed AM, Shamim EA, James-Newton L, Miller FW, Rider LG; Childhood Myositis Heterogeneity Collaborative Study Group: Immunogenetic risk and protective factors for juvenile dermatomyositis in Caucasians. Arthritis Rheum 2006, 54:3979-3987.

15. Wedderburn LR, McHugh NJ, Chinoy H, Cooper RG, Salway F, Ollier WE, McCann LJ, Varsani H, Dunphy J, North J, Davidson JE; Juvenile Dermatomyositis Research Group (JDRG): HLA class II haplotype and autoantibody associations in children with juvenile dermatomyositis and juvenile dermatomyositis-scleroderma overlap. Rheumatology (Oxford) 2007, 46:1786-1791.

16. Chinoy H, Payne D, Poulton KV, Fertig N, Oddis CV, Ollier WE, Cooper RG HLA-DPB 1*0101 discriminates between anti-Jo-1 and anti-PM-SCl antibody positive UK Caucasians with idiopathic inflammatory myopathy. Arthritis Rheum 2007, 56:5653.

17. West JE, Reed AM: Analysis of HLA-DM polymorphism in juvenile dermatomyositis (JDM) patients. Hum Immunol 1999, 60:255-258.

18. O'Hanlon TP, Rider LG, Mamyrova G, Targoff IN, Arnett FC, Reveille JD, Carrington M, Gao X, Oddis CV, Morel PA, Malley JD, Malley K, Shamim EA, Chanock SJ, Foster CB, Bunch T, Reed AM, Love LA, Miller FW: HLA polymorphisms in African-Americans with idiopathic inflammatory myopathy: allelic profiles distinguish patients with different clinical phenotypes and myositis autoantibodies. Arthritis Rheum 2006 54:3670-3681

19. Hirsch TJ, Enlow RW, Bias WB, Arnett FC: HLA-D related (DR) antigens in various kinds of myositis. Hum Immunol 1981, 3:181-186.

20. Reed AM, Stirling JD: Association of the HLA-DQA1*0501 allele in multiple racial groups with juvenile dermatomyositis. Hum Immuno/ 1995, 44:131-135

21. Friedman JM, Pachman LM, Maryjowski ML, Radvany RM, Crowe WE, Hanson $V$, Levinson JE, Spencer CH: Immunogenetic studies of juvenile dermatomyositis: HLA-DR antigen frequencies. Arthritis Rheum 1983, 26:214-216.

22. Furuya T, Hakoda M, Higami K, Ueda H, Tsuchiya N, Tokunaga K, Kamatani N, Kashiwazaki S: Association of HLA class I and class II alleles with myositis in Japanese patients. J Rheumatol 1998, 25:1109-1114.

23. O'Hanlon TP, Miller FW: Genetic risk and protective factors for the idiopathic inflammatory myopathies. Curr Rheumatol Rep 2009, 11:287-294.

24. Mierau R, Dick T, Bartz-Bazzanella P, Keller E, Albert ED, Genth E, Yaneva M, Arnett FC: Strong association of dermatomyositis-specific Mi-2 autoantibodies with a tryptophan at position 9 of the HLA-DR beta chain. Arthritis Rheum 1996, 39:868-876.

25. O'Hanlon TP, Carrick DM, Targoff IN, Arnett FC, Reveille JD, Carrington M, Gao X, Oddis CV, Morel PA, Malley JD, Malley K, Shamim EA, Rider LG, Chanock SJ, Foster CB, Bunch T, Blackshear PJ, Plotz PH, Love LA, Miller FW: Immunogenetic risk and protective factors for the idiopathic inflammatory myopathies: distinct HLA-A, $-B,-C W_{1}-D R B 1$, and -DQA1 allelic profiles distinguish European American patients with different myositis autoantibodies. Medicine (Baltimore) 2006, 85:111-127.

26. Shamim EA, Rider LG, Pandey JP, O'Hanlon TP, Jara LJ, Samayoa EA, BurgosVargas R, Vazquez-Mellado J, Alcocer-Varela J, Salazar-Paramo M, Kutzbach AG, Malley JD, Targoff IN, Garcia-De la Torre I, Miller FW: Differences in idiopathic inflammatory myopathy phenotypes and genotypes between Mesoamerican Mestizos and North American Caucasians: ethnogeographic influences in the genetics and clinical expression of myositis. Arthritis Rheum 2002, 46:1885-1893.

27. Marguerie C, Bunn CC, Copier J, Bernstein RM, Gilroy JM, Black CM, So AK, Walport MJ: The clinical and immunogenetic features of patients with autoantibodies to the nucleolar antigen PM-Scl. Medicine (Baltimore) 1992 71:327-336

28. Oddis CV, Okano Y, Rudert WA, Trucco M, Duquesnoy RJ, Medsger TA Jr:
Serum autoantibody to the nucleolar antigen PM-Scl. Clinical and immunogenetic associations. Arthritis Rheum 1992, 35:1211-1217.

29. Love LA, Leff RL, Fraser DD, Targoff IN, Dalakas M, Plotz PH, Miller FW: A new approach to the classification of idiopathic inflammatory myopathy: myositis-specific autoantibodies define useful homogeneous patient groups. Medicine (Baltimore) 1991, 70:360-374.

30. Arnett FC, Hirsch TJ, Bias WB, Nishikai M, Reichlin M: The Jo-1 antibody system in myositis: relationships to clinical features and HLA.J Rheumatol 1981, 8:925-930.

31. Goldstein R, Duvic M, Targoff IN, Reichlin M, McMenemy AM, Reveille JD, Warner NB, Pollack MS, Arnett FC: HLA-D region genes associated with autoantibody responses to histidyl-transfer RNA synthetase (Jo-1) and other translation-related factors in myositis. Arthritis Rheum 1990, 33:1240-1248.

32. Chinoy H, Salway F, Fertig N, Oddis CV, Ollier WE, Cooper RG: Clinical, serological and HLA profiles in non-Caucasian UK idiopathic inflammatory myopathy. Rheumatology (Oxford) 2009, 48:591-592.

33. Pachman LM, Liotta-Davis MR, Hong DK, Kinsella TR, Mendez EP, Kinder JM, Chen EH: TNFalpha-308A allele in juvenile dermatomyositis: association with increased production of tumor necrosis factor alpha, disease duration, and pathologic calcifications. Arthritis Rheum 2000, 43:2368-2377.

34. Werth VP, Callen JP, Ang G, Sullivan KE: Associations of tumor necrosis factor alpha and HLA polymorphisms with adult dermatomyositis: implications for a unique pathogenesis. J Invest Dermatol 2002, 119:617-620.

35. Hassan AB, Nikitina-Zake L, Sanjeevi CB, Lundberg IE, Padyukov L: Association of the proinflammatory haplotype (MICA5.1/TNF2/TNFa2/DRB1*03) with polymyositis and dermatomyositis. Arthritis Rheum 2004, 50:1013-1015.

36. Mamyrova G, O'Hanlon TP, Sillers L, Malley K, James-Newton L, Parks CG, Cooper GS, Pandey JP, Miller FW, Rider LG: Cytokine gene polymorphisms as risk and severity factors for juvenile dermatomyositis. Arthritis Rheum 2008 58:3941-3950

37. Chinoy H, Salway F, John S, Fertig N, Tait BD, Oddis CV, Ollier WE, Cooper RG: Tumour necrosis factor-alpha single nucleotide polymorphisms are not independent of HLA class I in UK Caucasians with adult onset idiopathic inflammatory myopathies. Rheumatology (Oxford) 2007, 46:1411-1416.

38. Candore G, Lio D, Colonna Romano G, Caruso C: Pathogenesis of autoimmune diseases associated with 8.1 ancestral haplotype: effect of multiple gene interactions. Autoimmun Rev 2002, 1:29-35.

39. Lio D, Candore G, Colombo A, Colonna Romano G, Gervasi F, Marino V, Scola $L$, Caruso C: A genetically determined high setting of TNF-[alpha] influences immunologic parameters of HLA-B8,DR3 positive subjects: implications for autoimmunity. Hum Immunol 2001, 62:705-713.

40. Jacob CO, Fronek Z, Lewis GD, Koo M, Hansen JA, McDevitt HO: Heritable major histocompatibility complex class II-associated differences in production of tumor necrosis factor alpha: relevance to genetic predisposition to systemic lupus erythematosus. Proc Natl Acad Sci U S A 1990, 87:1233-1237.

41. Szodoray P, Alex P, Knowlton N, Centola M, Dozmorov I, Csipo I, Nagy AT, Constantin T, Ponyi A, Nakken B, Danko K: Idiopathic inflammatory myopathies, signified by distinctive peripheral cytokines, chemokines and the TNF family members B-cell activating factor and a proliferation inducing ligand. Rheumatology 2010, 49:1867-1877.

42. Tezak Z, Hoffman EP, Lutz JL, Fedczyna TO, Stephan D, Bremer EG, Krasnoselska-Riz I, Kumar A, Pachman LM: Gene expression profiling in DQA $1 * 0501+$ children with untreated dermatomyositis: a novel model of pathogenesis. J Immunol 2002, 168:4154-4163.

43. Cullen M, Perfetto SP, Klitz W, Nelson G, Carrington M: High-resolution patterns of meiotic recombination across the human major histocompatibility complex. Am J Hum Genet 2002, 71:759-776.

44. Chinoy H, Payne D, Poulton KV, Fertig N, Betteridge Z, Gunawardena H, Davidson JE, Oddis CV, McHugh NJ, Wedderburn LR, Ollier WE, Cooper RG; UK Adult Onset Myositis Immunogenetic Collaboration \& UK Juvenile Dermatomyositis Research Group: HLA-DPB1 associations differ between DRB1*03 positive anti-Jo- 1 and anti-PM-Scl antibody positive idiopathic inflammatory myopathy. Rheumatology 2009, 48:1213-1217.

45. Werth VP, Berlin JA, Callen JP, Mick R, Sullivan KE: Mannose binding lectin (MBL) polymorphisms associated with low MBL production in patients with dermatomyositis. J Invest Dermatol 2002, 119:1394-1399.

46. O'Hanlon TP, Rider LG, Schiffenbauer A, Targoff IN, Malley K, Pandey JP, Miller FW: Immunoglobulin gene polymorphisms are susceptibility factors in clinical and autoantibody subgroups of the idiopathic inflammatory 
myopathies. Arthritis Rheum 2008, 58:3239-3246.

47. Vang T, Miletic AV, Bottini N, Mustelin T: Protein tyrosine phosphatase PTPN22 in human autoimmunity. Autoimmunity 2007, 40:453-461.

48. Rieck M, Arechiga A, Onengut-Gumuscu S, Greenbaum C, Concannon P, Buckner JH: Genetic variation in PTPN22 corresponds to altered function of T and B lymphocytes. J Immunol 2007, 179:4704-4710.

49. Chinoy H, Platt H, Lamb JA, Betteridge Z, Gunawardena H, Fertig N, Varsani $H$, Davidson J, Oddis CV, McHugh NJ, Wedderburn LR, Ollier WE, Cooper RG; UK Adult Onset Myositis Immunogenetic Collaboration and the Juvenile Dermatomyositis Research Group: The protein tyrosine phosphatase N22 gene is associated with juvenile and adult idiopathic inflammatory myopathy independent of the HLA 8.1 haplotype in British Caucasian patients. Arthritis Rheum 2008, 58:3247-3254.

50. Chinoy H, Salway F, Fertig N, Tait BD, Oddis CV, Ollier WE, Cooper RG: Monocyte chemotactic protein-1 single nucleotide polymorphisms do not confer susceptibility for the development of adult onset polymyositis/ dermatomyositis in UK Caucasians. Rheumatology (Oxford) 2007, 46:604-607.

51. Chinoy H, Salway F, John S, Fertig N, Tait BD, Oddis CV, Ollier WE, Cooper RG: Interferon-Gamma and Interleukin-4 Gene polymorphisms in UK caucasian idiopathic inflammatory myopathy patients. Ann Rheum Dis 2007, 66:970-973.

52. Chinoy H, Lamb JA, Ollier WE, Cooper RG: An update on the immunogenetics of idiopathic inflammatory myopathies: major histocompatibility complex and beyond. Curr Opin Rheumatol 2009, 21:588-593.

53. Mastaglia FL, Needham M, Scott A, James I, Zilko P, Day T, Kiers L, Corbett A, Witt CS, Allcock R, Laing N, Garlepp M, Christiansen FT: Sporadic inclusion body myositis: HLA-DRB1 allele interactions influence disease risk and clinical phenotype. Neuromuscul Disord 2009, 19:763-765.

54. Needham M, James I, Corbett A, Day T, Christiansen F, Phillips B, Mastaglia FL: Sporadic inclusion body myositis: phenotypic variability and influence of HLA-DR3 in a cohort of 57 Australian cases. J Neurol Neurosurg Psychiatry 2008, 79:1056-1060.

55. Askanas V, Engel WK: Proposed pathogenetic cascade of inclusion-body myositis: importance of amyloid-beta, misfolded proteins, predisposing genes, and aging. Curr Opin Rheumatol 2003, 15:737-744.

56. Greenberg SA, Sanoudou D, Haslett JN, Kohane IS, Kunkel LM, Beggs AH, Amato AA: Molecular profiles of inflammatory myopathies. Neurology 2002, 59:1170-1182.

doi:10.1186/ar3327

Cite this article as: Chinoy $\mathrm{H}$, et al.: Recent advances in the immunogenetics of idiopathic inflammatory myopathy. Arthritis Research \& Therapy 2011,

13:216 